\title{
SEGH live and beyond
}

\author{
M. J. Watts $(i)$ O. S. Humphrey • D. R. S. Middleton
}

Received: 7 September 2020/Accepted: 11 September 2020/Published online: 24 September 2020

(C) Springer Nature B.V. 2020

Throughout the COVID-19 crisis of 2020, we are all having to adapt to the situation whilst not knowing when we can return to some sense of normality and what that new 'normal' might look like. As we adjust to alternative ways of working, the Society for Environmental Geochemistry and Health (SEGH) International Board is working to evolve innovative ways of interacting with current and (hopefully) new members whilst encouraging back old friends. The first SEGH Live event via a Zoom webinar was set up in response to the COVID-19 crisis and the need to postpone the Kenya conference scheduled for July 2020 to July 2021. Many of the speakers were drawn from abstracts submitted for the Kenya conference, which enabled the rapid organisation of a programme on the 29/30 June. Presentations were supplemented by additional invited speakers to increase the variety of topics and geographic distribution. This article is to

M. J. Watts $(\bowtie) \cdot$ O. S. Humphrey

Inorganic Geochemistry, British Geological Survey,

Nottingham, UK

e-mail: mwatts@bgs.ac.uk

O. S. Humphrey

e-mail: olih@bgs.ac.uk

D. R. S. Middleton

Section of Environment and Radiation, International Agency for Research Cancer, World Health Organization, Lyon, France

e-mail: middletond@fellows.iarc.fr thank the participants for their enthusiasm and engagement in a new and interactive format spanning contributors from five continents.

The first SEGH Live event attracted some 100 registrations from across 35 countries, with 29 presentations given from 16 countries. The meeting was hosted from Nottigham in the UK with the programme split across an afternoon and following morning to enable maximum participation across all time zones. Sessions were recorded and are available to SEGH members via www.segh.net through the SEGH members-only log-in area. The book of abstracts is available to download for anyone via the Previous Conference Abstract Books page https:// segh.net/conference-abstracts. Sessions were comprised of one 12-min 'keynote' presentation, followed by three to four back-to-back 5-min presentations, with time allowed for questions to be directed to the speakers as a group. Through the meeting, we as organisers and the participants became more proficient at handling and offering questions to the speakers.

The event hosted a good mix of established researchers and early career researchers providing discussion topics or communicating recent data from ongoing experiments and studies spanning the full range of SEGH interests from biology, ecology, medicine, epidemiology and nutrition through to agriculture, mining, the urban environment, industrial pollution, geology and technological developments, 
often with an overlap between disciplines, as is often the case for SEGH members. Discussions covered the study of naturally occurring processes, waste clean-up or impact of waste disposal along with receptor pathways including fauna/flora/human health indicators.

\section{Discussion forum}

At the end of the meeting, some of the SEGH international board members had the opportunity to introduce themselves and outline their interests. Please do approach board members if you have any enquiries for your region or research topic. An early career researcher prize provided by Springer Nature publications for a $\$ 250$ book voucher presented a tough choice out of an excellent line-up of presentations. First prize was awarded to Dr Felix Oniyje, a Postdoctoral Fellow from the International Agency for Research on Cancer in France for his presentation on a systematic review and meta-analysis of cancer among petroleum industry workers. Second prize was awarded to Haley MacLeod from Lakehead University in Canada who presented her PhD work on freshwater fish productivity and the implications of plastic pollution. Springer Nature also announced a new initiative to provide the best paper award submitted to the SEGH official journal Environmental Geochemistry and Health (EGAH) for an early career researcher in 2019. The SEGH international board unanimously voted for Daniel E. González-Santamaría (2019) paper entitled 'Impact of a tire fire accident on soil pollution and the use of clay minerals as natural geo-indicators' and was awarded with a $\$ 300$ book token. To all ECRs or their corresponding authors, when submitting ECR papers, please do tick the box to denote ECR paper. We were also able to communicate good news for EGAH, for which the 2019 impact factor increased again to 3.47 .

As we approach 2021, SEGH will celebrate its 50th anniversary for which activities are planned to include a series of review and discussion articles in EGAH, led by fellows of SEGH and supported by the ECR group. Additionally, smaller workshops or symposia will be arranged to supplement the main annual conference, for example, in British Columbia, Canada, in August 2021. The international board have assigned a group of board members to nurture and develop the ECR group beyond the limited activities to date. For example, ECRs will be involved more prominently in gaining work experience in reviewing and handling EGAH manuscripts alongside experienced editorial board members. All of these activities bear in mind the aspirations of the board set out in 2019 (Watts et al. 2019) and those of the early career researchers (Humphrey et al. 2020). Considerable progress has been made despite the COVID-19 crisis, but there is still plenty to do as we approach the 50th anniversary of SEGH.

\section{Conclusion}

The user experience was generally good with very positive feedback and surprise at the effectiveness of 5-min presentations. There was some debate within the SEGH board about increasing time as some presenters overran, but in general it was the 12-min presentations that overran slightly or slight technical difficulties, but time was built into the programme to account for this. The longer presentations were set up differently, in that as organisers we had the presentations in advance for the 5-min presentations which allowed us to check their length and control the pace to a greater degree, whereas the 12-min presenters had control of their own presentations by sharing their screens. With lessons learnt, we can certainly repeat the short formats to maintain the energy and interest displayed for a follow-up online event, but maintain greater control over the delivery of presentations and provide a template or maximum number of slides presenters can present. SEGH Live provided a forum for many people not able to attend international conferences, or at least every conference, and provided an opportunity to meet some of the international board. Where we need to develop further is to plan and facilitate greater interaction between delegates, and perhaps the SEGH Early Career Researcher group can come up with some bright ideas for this challenge. Whilst the SEGH Live event was incredibly engaging and resulted in many positive outcomes, such events will not replace physical conferences in the long term where face-to-face meetings and introductions can be made, particularly where new interactions and friendships can be forged informally during break times or social events. However, in the coming year, SEGH Live events will enable interactions to continue, whilst 
the COVID-19 crisis limits international travel and will perhaps in the long term be a useful approach to engage with members who do not have the resources to travel, provide more focussed events on topics or specific regions and potentially test a more flexible approach with either greater frequency or ad hoc occurrence as world events or hot research topics unfold for a more responsive approach. In this regard, SEGH Live formats will bridge gaps between face-toface meetings, enriching the member experience throughout the calendar. Certainly, concerns over everyone's carbon footprint besides financial resources will grow and, as SEGH Live evolves, it could provide some engagement between members from around the world without the need for travel.

The future of societies around the world will certainly be interesting to watch in the coming years, particularly with the accelerated uptake of communication channels. Further ideas are welcome from the SEGH membership on exploiting these opportunities.

\section{References}

González-Santamaría, D. E., et al. (2019). Impact of a tire fire accident on soil pollution and the use of clay minerals as natural geo-indicators. Environmental Geochemistry and Health. https://doi.org/10.1007/s10653-019-00485-2.

Humphrey, O. S., Middleton, D. R. S., Ahmad, S., et al. (2020). The Society for Environmental Geochemistry and Health (SEGH): Building for the future of early career researchers. Environmental Geochemistry and Health. https://doi.org/ 10.1007/s10653-020-00620-4.

Watts, M. J., An, T., Argyraki, A., et al. (2020). The Society for Environmental Geochemistry and Health (SEGH): building for the future. Environmental Geochemistry and Health, 42, 343-347. https://doi.org/10.1007/s10653-01900381-9.

Publisher's Note Springer Nature remains neutral with regard to jurisdictional claims in published maps and institutional affiliations. 